\title{
Should I Participate in a Business Accelerator?
}

\author{
Jon Eckhardt (University of Wisconsin-Madison)
}

KEYWORDS: Entrepreneurship, Innovation, Angel Funding, Venture Capital, Strategy.

Business accelerators are a relatively new source of potential support for startup companies. These organizations provide financing and services to entrepreneurs who are forming or are operating startup companies. While the number of business accelerators is growing rapidly worldwide, many experienced entrepreneurs don't understand how they operate and what they can do.

\section{History}

Two organizations are credited with launching the business accelerator industry: Y-Combinator, originally located in Cambridge, Massachusetts, and Techstars, of Boulder, Colorado. Y-Combinator was started in 2005, and Techstars launched their first program in 2007. Y-Combinator now operates from a single location in California's Silicon Valley, while Techstars operates a group of affiliated branded Techstars programs across the United States. In addition, the Techstars organization spawned the Global Accelerator Network, which is a member organization of 50 accelerators that share best practices and agree to adhere to a set of basic standards.

Since the industry is only 10 years old, rigorous academic research on the space is in its infancy. However, several companies that were early participants in business accelerators have achieved great success. For example, DropBox participated in YCombinator's program in in 2007 , and has reportedly raised over $\$ 1.1$ billion, and Twitch (formerly Justin.tv) also participated in Y-Combinator's 2007 class and was acquired by Amazon in 2014 for a reported $\$ 970$ million. These impressive outcomes suggest that business accelerators may have something to offer enterprising entrepreneurs.

\section{How Accelerators Work}

Accelerators make equity investments in groups of companies at a time - often termed classes or programs. Like venture funds, accelerators make

money from the management fees they charge investors, and by earning returns on their investments in the companies. Accelerators get their money back when a company they invested in achieves a liquidity event that returns capital to their investors. The types of possible liquidity events include the sale of a company to another firm, an Initial Public Offering, the sale of equity to another venture fund, or a management/employee-led buyout.

Companies that are accepted into an accelerator typically receive an equity investment, and all or part of the founding team are often required to work in a coworking space that is owned by the accelerator during the duration of the program. Programs typically run for 10 to 12 weeks and culminate in an event where entrepreneurs make a presentation to at least several hundred individuals - many of whom are active investors in startup companies.

Most business accelerators provide most or all of the following

1. Training. Many accelerators include classes and one-on-one custom training provided by the accelerator staff or guest speakers. Topics that are covered are typically best suited for firsttime entrepreneurs who are operating earlystage businesses: for example, how to work with investors.

2. Startup Advice. Accelerator staff and a network of volunteer mentors provide advice to the management teams of portfolio companies. Advisors provide startup expertise, management expertise and industry expertise relevant to the problems faced by the actual company.

3. Coworking space. Accelerators that require startups to operate in a specific location during the class typically provide office space as part of the funding package. Sharing space makes it easier for the accelerator staff to give the 
entrepreneurs training and advice, and imprint them with a common culture.

4. Funding. As venture funds, accelerators make investments in their portfolio companies. They also help those companies secure follow-on funding from other venture investors, including venture capital firms.

5. Networks. The most prominent business accelerators leverage social networks of potential investors, advisors, employees and industry experts to help their portfolio companies acquire resources and customers, and ultimately grow.

6. Reputation. While no peer-reviewed research has been done yet on this topic, anecdotal evidence suggests that being accepted into a high-status accelerator benefits startup companies and their founding teams. The potential effect of a company being accepted into a low-status accelerator is unclear, and remains a potentially important area of inquiry.

7. Monitoring. As organized venture funds, business accelerators have a fiduciary responsibility to oversee their investments on behalf of their investors. Investors in accelerator funds or in accelerator-backed companies may benefit from accelerators overseeing their investments.

Accelerators aim to accelerate the growth of their portfolio companies by combining these activities in an organized, yet intensive program. Entrepreneurs have said that participation in an accelerator is like being in boot camp.

\section{How They Differ From Angel Investors}

Angel capital has been a historically important source of funding for early-stage companies. In the most basic form, angel investors invest as individuals in specific companies. Some angel investors organize as groups to reduce costs and manage deal flow, and some angel investors make investments through organized angel funds.

Because business accelerators make seed stage investments, they can be classified as a type of angel investors. A key difference: angel investors typically provide capital but little in the way of additional services, while business accelerators provide services that hopefully increase the success of their portfolio companies. This means that the accelerator is more expensive to run.

\section{How They Differ From Business Incubators}

Business incubators have been around for decades longer than business accelerators, and also bring young companies together in a common workspace. The fundamental difference between business incubators and business accelerators is that business incubators are generally real estate operations supported by tenants paying rent for the right to occupy space in the incubator facility. This means that the incubator manager's top priority is to make sure that the space has enough paying tenants.

Since business accelerators are venture funds driven by investment returns, their incentive is to try to get the companies in their portfolio to grow as quickly as possible so they can achieve a favorable exit. The companies in an accelerator's active class typically don't pay rent, and the accelerator aims to help them outgrow the accelerator space and move into their own facilities as quickly as possible. As business accelerators make equity investments in startup companies and are typically paid only if the company is successful, the incentives of business accelerators in most cases are more closely aligned than business incubators with the incentives of entrepreneurs.

\section{How They Bring High-Powered Incentives to Support Entrepreneurs}

High-powered employee incentives are incentive schemes that provide high economic value to employees who meet objectives, and zero to low economic value to employees who do not perform well. Research has shown that high-powered incentives encourage employees to take on potentially high-value projects where the outcome is unknown. Professor Todd Zenger at the University of Washington has several papers that make the case that startup companies are particularly good at encouraging innovation, by rewarding employees who take on risky projects.

In most cases, private business accelerators don't pay off for managers and investors if their portfolio companies don't do well: for example, if the liquidity events do not yield sufficient capital to repay investors and provide managers with sufficient compensation. But being part of an accelerator can also pay off big if the liquidity event generates a handsome return. Hence an 
argument can be made that business accelerators provide high-powered incentives for managers and investors to help entrepreneurs build economic value. This might explain the strong resemblance between services (advice, capital, training, network) provided by the top venture capital firms in the country and the top business accelerators in the country.

Non-profit and publicly funded accelerators may lack high-powered incentives. So while they may look like private accelerators in terms of inputs, they may ultimately fail to yield the same benefits.

\section{Key Questions Before You Participate in a Business Accelerator}

Accelerators are active, involved investors. Hence, I recommend that companies conduct the same due diligence on accelerators as they would for any significant business partner. Here are some important sources of information:

- $\quad$ Fund managers and employees of the business accelerator

- $\quad$ Former fund managers and former employees of the business accelerator

- $\quad$ CEOs of current and former portfolio companies, including companies that are no longer in operation

- $\quad$ Public databases that track startups and business accelerators, such as Crunchbase (crunchbase.com), Angel List (angel.co), and Seed-DB (http://www.seed-db.com/)

- $\quad$ Startup attorneys who have represented firms that have been financed by the accelerator

Below are some questions worth asking as you consider working with specific accelerators. They include not only questions about the accelerator itself, but also some internal due diligence to see if it makes sense to work with an accelerator at all.

\section{Questions About Yourself and Your Company}

Are my goals for the company compatible with the goals of business accelerators? Business accelerators are becoming an important part of the venture capital focused model of entrepreneurship. This means that most business accelerators are seeking to fund gazelles, which are companies that will either grow rapidly or fail in a short period of time. If you and your team are committed to building a high-growth company, and if your company is pursuing a potentially large market, then your goals are likely to be consistent with participating in a business accelerator.

Is my company at the appropriate stage of development? Business accelerators are generally the most appropriate for seed stage businesses with some revenue but little or no outside capital. More advanced companies do participate in business accelerators, but it often requires early investors support the business accelerator to purchasing equity at price lower than that which was paid by existing investors. Investors do support this option in some cases if they believe participation in a business accelerator will ultimately increase the value of their stake in the business.

Is my management team prepared to work out of a coworking space? Many, but not all, business accelerators require the management team to commit to working at least part of the week out of the accelerator coworking space. This improves the chance that your management will get the most out of what the accelerator has to offer, but not every company can do this.

Does my management team embrace a culture of learning? Many accelerators try to increase the growth rates of companies in their portfolio by pushing the companies to learn faster. This is incredibly effective for management teams that are willing to embrace this approach, but also destructive for those that can't.

\section{Questions About the Accelerator}

How does the accelerator perform on standard industry performance metrics? Metrics to assess the quality of business accelerators are likely to change as the industry evolves. Circa January 2014, important metrics include:

- Number of applications for each class. This is an indication of the overall interest in the accelerator. An accelerator with fewer than 200 applicants is probably not competitive.

- Number of companies accepted into each class. Programs that accept more companies spend less time on developing each one. If an 
accelerator is taking on more than 10 companies at a time, it probably makes sense to dive into questions about how much access each entrepreneur has with accelerator staff.

- Acceptance rate (number of companies accepted/number of applicants). Acceptance rates for established programs are typically lower than $5 \%$.

- Average, total, minimum and maximum amount of funds raised for each company upon completion of the business accelerator program. Relevant metrics here are likely to be cyclical, and hence should be benchmarked against industry data at the time of application.

- Number of classes completed. The barriers to entry into the business accelerator business are low, but success is difficult to achieve. Programs that have stood the test of time by completing multiple programs have passed a significant milestone.

Are the people involved in the accelerator people you want to have as co-owners in your business going forward? The business accelerator should be thought of as a long- term partner in your business. As significant owners of your business, they have the opportunity to either enhance or impede its development.

How transparent is the accelerator? Several early accelerators have been incredibly open in sharing operating documents, deal terms, and even performance data. This transparent approach has permeated the industry and has helped to fuel an "entrepreneur friendly" culture.

What is the reputation of the accelerator, and of the other companies in the portfolio. Are these companies that you wish to affiliate with? For better or worse, reputation matters in business. A business accelerator's reputation can benefit or potentially harm the companies in its portfolio.

How extensive and effective is the network tied to the business accelerator? A major benefit of participating in a business accelerator is that portfolio companies have access to its network of investors, customers and advisors. So it's important to examine the quality of the network and ts trajectory.

Access to the accelerator management team. If you like the individuals who are managing the accelerator, it is important to make sure you will have access to them once you are accepted into the program.

Does the accelerator offer competitive terms, and is the structure of their investment likely to facilitate or impede follow-on financing? Because business accelerators tend to finance businesses that are mostly comparable based on stage and industry sector, standardized terms and pricing have developed. Combined with the industry norm of transparency, this is a favorable development for entrepreneurs attempting to finance early stage businesses.

However, some bad deals offered by accelerators should probably not be accepted by startup companies. While entrepreneurs typically focus on the valuation and the amount of cash that is provided, they also must make sure that the terms of the deal don't limit the company's ability to get future funding. Aggressive deal terms are still a big problem in early stage financing, so it may be wise for companies to engage an experienced startup attorney to guide them through negotiations with accelerators.

\section{Summary}

As business accelerators can provide financing and expertise to early stage entrepreneurs, they are a welcome addition to the global entrepreneurial ecosystem. However, as with all business transactions, it is important to shop around and conduct careful due diligence before accepting an investment from a business accelerator. 